\title{
Environmental Policy and Industry Location: The Case of the U.S. Livestock Industry
}

\author{
Dooho Park, Andrew Seidl, and Stephen Davies*
}

\begin{abstract}
The relationship between state-level environmental regulations and firm location decisions in the U.S. livestock industry is explored. We focus on the overall size of the livestock industry by state and over time. We find that the effects of differences in productive input costs across states, for instance property tax and local slaughter capacity, are consistent with expectations. We differentiate between the written stringency of environmental policy and its actual enforcement. Enforcement of environmental regulations, as seen by a state's tendency to levy fines and the staff devoted to monitoring, seems to affect industry location negatively. However, the written regulatory stringency effects are positive, suggesting that a political response occurs when livestock operations grow, but only the choice to enforce actually alters the location decision of producers.
\end{abstract}

\section{INTRODUCTION}

State and local concerns surrounding the environmental management of livestock operations have created a mosaic in the state-level environmental policy milieu. In 1998, 23 states and the federal government considered legislation to monitor more closely emissions from livestock operations (Edelman et al. 1999). The environmental policies that have been applied to livestock are directed generally toward larger, incorporated, or vertically integrated operations (Martin and Zering 1997; Hubbell 1997; Metcalfe 2000). These policies tend to address ground and surface water concerns and, increasingly, air quality issues.

Livestock operation location is determined by access to input and output markets, management technology employed, and environmental attributes of the land, such as precipitation, temperature, humidity, and soil type/quality (Metcalfe and Beghin 1999; Metcalfe 2000). Recent changes in production technology and lower transportation costs have increased location alternatives and altered industry structure by weakening the geographic link between feed supplies and livestock. Economic theory suggests that productive and consumptive externalities provide the impetus for public policy; so, policy is reactive. However, experience tells us that policy can be put in place in anticipation of social costs; so, policy can be proactive. Once policies are in place, firms will incorporate costs of compliance, adjusted for the risk and cost of noncompliance, into their production functions; industry thus reacts to positive and negative financial incentives.

*Senior Researcher, Korean Institute of Construction Technology, Seoul, Korea; and Assistant Professor and Professor, Department of Agricultural and Resource Economics, Colorado State University, Fort Collins. Without implication, the authors would like to acknowledge the thoughtful review and comments of three anonymous reviewers, Marshall Frasier, and Jessica Davis. Errors remain unintentional and ours. The Colorado State University Agricultural Experiment Station, Colorado State University Cooperative Extension, and the Farm Foundation provided financial and/or material support for this research. 
The literature on this subject commonly poses this classical "chicken and egg" problem. The stringency of environmental regulations is either (a) the result of or (b) the catalyst for change in livestock industry location decisions (Mo and Abdalla 1998; Martin and Norris 1998). Alternatively, the willingness and ability to enforce these regulations, rather than their written stringency, may affect location decisions. Although policy debates over the environmental management of the livestock industry are prominent in public discourse, little empirical evidence testing these hypothesized relationships is found in the literature.

In this paper, state-level (48 states) effects of environmental policy across livestock and poultry species (i.e., hogs, beef cattle, dairy, and chickens) over the three decades since the passage of the federal Clean Water Act are examined. Indices illustrating the relative stringency of environmental regulations as they are written and evidence of their enforcement across states are developed for the purposes of this analysis. Changes in livestock industry size are expected to reflect the imposition of new environmental policies across states. The written stringency of environmental regulation coupled with greater evidence of monitoring and enforcement of regulations are expected to guide most strongly the evolution of the livestock industry when location factors are most flexible. In addition to environmental policy effects, the included variables control for natural endowments of individual states, economic factors, and business climate.

\section{PUBLISHED APPROACHES AND EVIDENCE}

While substantial research relates location decisions of manufacturing firms to environmental policy, the literature relating environmental policy and the livestock industry is fairly thin. Persistent challenges in compiling appropriate data and attendant analytical difficulties have contributed to the lack of published research in this area. Rather than enter the debate over whether large confined animal feeding operations are "farms" or "factories," we draw insights from the broader literature base.

\section{Environmental Policy and Manufacturing}

The manufacturing sector literature is conveniently bifurcated into surveys of manufacturers regarding factors they consider in plant location, and secondary analyses of characteristics theoretically presumed to affect firm location (Mo and Abdalla 1998). Within the manufacturing sector, the industries studied to date include plants of Fortune 500 manufacturers (Bartik 1988), automotive plant location (McConnell and Schwab 1990), industries falling under ozone regulations (Henderson 1996), and the pulp and paper industry (Gomez, Love, and Burton 1998). This area of inquiry has employed a variety of analytical techniques, including microeconomic conditional logit specifications (McFadden 1974; Bartik 1988; McConnell and Schwab 1990; Levinson 1996; Gray 1997), a microeconomic fixed effects model of panel data (Henderson 1996), and a macroeconomic stationary Markov chain model (Gomez, Love, and Burton 1998). 
Most published results from the manufacturing sector literature suggest that geographic environmental policy variation has little effect on plant location (Bartik 1988; McConnell and Schwab 1990; Levinson 1996), potentially due to low expected compliance costs. However, evidence of a negative correlation between the stringency of environmental policy and plant location decisions has been shown in some cases (Henderson 1996; Gray 1997). One study (Gomez, Love, and Burton 1998) shows that the policy setting influences plant capacity decisions.

\section{Environmental Policy and the Livestock Industry}

Unlike analyses of the manufacturing sector, most research on livestock is industry (species) specific. Taken as a body of research, the results are inconclusive. Thurow and Holt (1997) find that the timing and sequencing of policy signals influence compliance behavior and options for Texan and Floridian dairies; thus, policy is seen to influence firm decision making. Mo and Abdalla (1998) were unable to find a significant relationship between hog farm location and inventory decisions and environmental policy stringency in the 13 leading hog producing states. Martin and Norris (1998) summarize previous work on environmental policy and livestock industry structure and conclude that it is more likely that industry drives policy rather than the converse.

Metcalfe and Beghin (1999) extend Mo and Abdalla's (1998) work by including four policy stringency indices, expanding the number of states to include the 27 most important hog producing states, and increasing the length of time examined (1984-1998). This work also addresses the potential endogeneity of environmental regulations and hog production decisions, which should formally test Martin and Norris' (1998) conclusions. Although Metcalfe and Beghin (1999) were able to conclude that traditional factors (including corn price, transportation costs, and agricultural infrastructure) were significant predictors of hog production and location decisions, they were unable to establish a link between environmental policy stringency and the location decisions of hog operations.

\section{DATA AND ANALYTICAL APPROACH}

\section{Data Compilation and Manipulation}

The data required for this analysis include animal inventories by state over time. Agricultural census data (USDA-NASS 1999a) were compiled for 48 states, excluding Alaska and Hawaii, in the dairy, swine, beef cattle, and broiler industries over almost three decades (1969 to 1997). Census data provided the raw information for the calculation of total animal units, beef-corn and hog-corn price ratios, and slaughter capacity. The environmental regulation factors were based upon the "1998 National Survey of Animal Confinement Policies" database containing information from 48 states (Edelman et al. 1999). The National Agricultural Statistics Service (NASS) "Historical Data" provided property tax, average annual precipitation, unemployment rate, and land value information (USDA-NASS 1999b). Data sources, units, and the mean values of the variables are summarized in Table 1. 
TABLE 1

List of Variables

\begin{tabular}{lrrr}
\hline Variable $^{\mathrm{a}}$ & Units & Abbreviation & Mean Value \\
\hline Total animal units $_{\text {Beef-corn price ratio }}$ & $\mathrm{AU}$ & Anitot & $2,889,344$ \\
Hog-corn price ratio & $\mathrm{B} / \mathrm{C}$ & Bratio & 170.626 \\
Slaughter capacity & $\mathrm{H} / \mathrm{C}$ & Hratio & 27.246 \\
Land value & Proportion & Slaught & 373.51 \\
Unemployment rate & $\$ /$ acre & Landval & 994.934 \\
Population density & $\%$ & Unemp & 6.238 \\
& People/ Private & Popden & 308.453 \\
Average annual precipitation & land $(1,000$ acres) & & \\
Property tax & Inches & Precipt & 36.631 \\
Regulatory stringency index & $\$ /$ acre & Protax & 7.050 \\
Fines imposed & $(0,1, \ldots, 19)$ & Regula & 13.471 \\
Staffing level & $(0,1)$ & Levfine & 2.573 \\
Anti-corporation farm law & $($ FTEs) & Staff & 0.583 \\
Local agricultural zoning & $(0,1)$ & Corp & 0.146 \\
\hline
\end{tabular}

${ }^{2}$ Sources: NASS-USDA: Anitot, Bratio, Hratio, Slaught, Landval, Unemp, Precipt, and Protax; Census Bureau: Popden; Task Force Survey: Regula, Levfine, Staff, Corp, and Zoning.

Note: Slaughter Capacity $=($ Beef Slaughter+Hog Slaughter) /Total Animal Inventory.

Annual state total animal inventories (Anitot) were calculated using animal unit equivalents developed by the U.S. Environmental Protection Agency. A beef cow is one standard animal unit (AU), while a dairy cow is $1.4 \mathrm{AU}$. Each hog is $0.4 \mathrm{AU}$, and a chicken weighs in at $0.01 \mathrm{AU}$ (dry system, $0.03 \mathrm{AU}$ wet system). Values for noncensus years were assigned using linear extrapolation of intracensus trends.

State-level beef-corn and hog-corn price ratios were included to represent relative profitability across location and time. Labor availability may attract more operations and livestock to a state, so state unemployment rates were used to capture the contention that relatively loose labor markets might encourage industry expansion. A measure of the combined annual beef and hog slaughtering capacity by state, divided by total animal inventories, was included as an indicator of transportation costs. ${ }^{1}$ The beef-corn price ratio (Bratio), hog-corn price ratio (Hratio), unemployment rate (Unemp), and slaughter capacity (Slaught) are expected to correlate positively with total state livestock inventory.

Greater livestock-human interaction is likely to result in more conflict and greater perceived negative externalities. Since both people and livestock spend most of their time on private land, the likelihood of their interaction increases as their populations increase and as developable land decreases. Although sheep and cattle are grazed at low densities on public lands in western states, the base of livestock operations must be on private land where it is subject to local, state, and federal regulations. Particularly in the West, where 30 to 90 percent of the land area is public, population density calculations based on the size of the state are likely to skew results more than calculations excluding public lands. Thus, population data and the areas in private land by state over five censuses were compiled 1 Due to the close correlation between animal inventory and slaughter capacity, the actual variable used in the analysis is: (Beef Slaughter + Hog Slaughter)/Total Animal Inventory. This provided a better proxy for the existence of capacity. 
$(1960,1970,1980,1990$, and 2000) to develop a measure of population density on developable land by state and over time. Higher population density (Popden) in the state is expected to correlate with less animal inventory growth.

Livestock production costs are likely to vary across states in a number of dimensions, including land prices, property tax rates, and climatic features of the landscape. Land prices (Landval) are a broad indicator of an important production cost in the livestock industry, reflecting population pressure, land use policies, resident wealth and income, and current and anticipated land use. State property tax (Protax) is also a broad indicator of a state's business climate. Though imprecise for agricultural regions of larger states, state average annual precipitation (Precipt) was included to represent state-level climatic variation and environmental vulnerability. Land prices (Landval), property tax (Protax) and precipitation (Precipt) are expected to correlate negatively with the state livestock inventory.

Compliance with environmental regulations constitutes an additional cost of livestock production. An index (Regula) was constructed to represent the general stringency of state regulations using recent survey information from Edelman et al. (1999). The index was generated from an unweighted sum of affirmative responses to 29 regulatory stringency-related survey questions. Nineteen affirmative responses were the maximum observed, while zero affirmative responses provided the lower bound on the regulatory stringency index. Laws prohibiting corporate ownership (Corp) of livestock operations and providing for agricultural districting (Zoning), potentially indicative of the strength of local "right to farm" legislation, were included as dummy variables due to their particular timeliness and interest.

The decision to comply with regulations, and therefore the expected cost of regulatory compliance, is dependent upon the likelihood of being caught out of compliance and the size of the penalty for noncompliance. Neither active enforcement (fines imposed over time or evidence of compliance with policies) nor effectiveness (changes in water or air quality) measures are available in a usable form. As imperfect substitutes for enforcement information, a dummy variable (Levfine) indicating whether or not fines had been levied and a count variable indicating the number of staff (Staff) dedicated to monitoring and enforcement were included.

In our analysis, statistically significant results contrary to our expectations can often be interpreted as the influence of environmental policy. Ideally, through the use of lagged effects, analysis of a time series of policy variation would facilitate the discovery of whether policy leads industry or industry drives policy. Unfortunately, such a time series was not available for all states over the period of examination, so the effectiveness of policy is inferred from time invariant and contemporaneous relationships. For example, we expect that greater monitoring and enforcement of regulations should increase livestock production costs and negatively influence state-level livestock inventories; the industry is driven by the regulatory climate. Alternatively, a positive sign on the number of staff devoted to 
enforcing environmental regulations could be interpreted as indicating that states with larger livestock industries have a greater need for enforcement; there are more problem producers and the policy is driven by the industry. Similar arguments can be made regarding the significance of the other regulatory variables as well.

TABLE 2

Animal Inventory: State Rank and Animal Units (beef cattle, hogs, dairy cows and poultry),

Selected Years

\begin{tabular}{|c|c|c|c|c|c|c|}
\hline State & 1997 & $\begin{array}{l}\text { Rank } \\
1985\end{array}$ & 1969 & $\begin{array}{l}\text { Inventory } \\
\text { (1000 AU) }\end{array}$ & $\begin{array}{c}1997 \\
\% \text { of total } \\
\text { inventory }\end{array}$ & $\begin{array}{c}\text { Cumulative \% of } \\
\text { inventory }\end{array}$ \\
\hline $\mathrm{TX}$ & 1 & 1 & 2 & 15,461 & 11.12 & 11.12 \\
\hline IA & 2 & 2 & 1 & 10,015 & 7.20 & \\
\hline NE & 3 & 3 & 3 & 8,307 & 5.97 & \\
\hline $\mathrm{CA}$ & 4 & 8 & 8 & 7,321 & 5.26 & \\
\hline KS & 5 & 4 & 5 & 7,269 & 5.23 & 34.78 \\
\hline OK & 6 & 5 & 7 & 6,162 & 4.43 & \\
\hline MO & 7 & 9 & 13 & 6,049 & 4.35 & \\
\hline WI & 8 & 7 & 9 & 5,644 & 4.06 & \\
\hline MN & 9 & 6 & 4 & 5,562 & 4.00 & \\
\hline NC & 10 & 13 & 11 & 5,024 & 3.61 & 55.23 \\
\hline SD & 11 & 11 & 6 & 4,438 & 3.19 & \\
\hline $\mathrm{CO}$ & 12 & 15 & 15 & 3,769 & 2.71 & \\
\hline IL & 13 & 14 & 18 & 3,525 & 2.53 & \\
\hline PA & 14 & 12 & 12 & 3,227 & 2.32 & \\
\hline IN & 15 & 16 & 16 & 2,956 & 2.13 & 68.11 \\
\hline $\mathrm{KY}$ & 16 & 18 & 17 & 2,886 & 2.07 & \\
\hline MT & 17 & 19 & 19 & 2,718 & 1.95 & \\
\hline $\mathrm{OH}$ & 18 & 17 & 14 & 2,592 & 1.86 & \\
\hline NY & 19 & 20 & 28 & 2,500 & 1.80 & \\
\hline TN & 20 & 23 & 20 & 2,450 & 1.76 & 77.56 \\
\hline $\mathrm{AR}$ & 21 & 27 & 23 & 2,334 & 1.68 & \\
\hline ID & 22 & 28 & 25 & 2,301 & 1.65 & \\
\hline FL & 23 & 25 & 27 & 2,169 & 1.56 & \\
\hline VA & 24 & 22 & 31 & 2,002 & 1.44 & \\
\hline ND & 25 & 21 & 22 & 1,995 & 1.43 & 85.32 \\
\hline NM & 26 & 10 & 33 & 1,992 & 1.43 & \\
\hline MI & 27 & 24 & 21 & 1,909 & 1.37 & \\
\hline GA & 28 & 31 & 24 & 1,751 & 1.26 & \\
\hline WY & 29 & 30 & 10 & 1,736 & 1.25 & \\
\hline OR & 30 & 32 & 26 & 1,721 & 1.24 & 91.87 \\
\hline Others & $31-48$ & N/A & N/A & 11,306 & 8.13 & 100.00 \\
\hline
\end{tabular}

Source: Census of Agriculture 1969, 1985 and 1997

The general behavior of the dependent variable (Anitot) over time and space is summarized in Table 2, where the livestock inventory rank of each state in 1969, 1985, and 1997 is provided. In addition, the total livestock inventory by state in 1997, the percentage that each state accounts for, and the cumulative percentages of all states in the ranking are shown. Overall, those states that began the time series large remained large over the period, with some notable exceptions. Of the top ten livestock-producing states in 1997, accounting for about 55 percent of total livestock inventory, eight were among the top ten in 1969. The most notable 
increases in ranking were California, which moved from 8th in 1969 to 4th in 1997, and Missouri, which grew from 13th in 1969 to 7th in 1997. North Carolina, often thought to exhibit rapid growth in livestock production, particularly hogs, only increased from 11th in 1969 to 10th in 1997. The next nine states accounted for about 20 percent of total U.S. livestock inventories in 1997. In that group, South Dakota declined from 6th to 11th, while Illinois grew five positions from 18th to 13th and New York grew from 28th to 19th. The remaining 29 states contributed the final 25 percent total livestock inventory in 1997. The most dramatic change in that group was New Mexico, which grew from 33rd in 1969 to 10th in 1985, and then declined to 26th in 1997. Wyoming declined 19 places, from 10th in 1969 to 29th in 1997.

In summary, the model in this paper can be represented functionally in two broad categories of variables as

$$
Y_{i t}=f\left(X_{i t}, Z_{i}\right) \quad(i=1, \ldots, N ; t=1, \ldots T),
$$

where the dependent variable $\left(Y_{i t}\right)$ is specified as total livestock inventory in a state in a given year (Anitot). The matrix of time-varying independent variables $\left(X_{i t}\right)$ consists of the following principal categories: Natural Endowments (Precipt), Economic Factors (Bratio, Hratio, Slaught), and Business Climate (Landval, Unemp, Protax, Popden). The matrix of $\left(\mathrm{Z}_{\mathrm{i}}\right)$ specifies the stringency and enforcement of state environmental policies (Regula, Levfine, Staff, Corp, and Zoning), which are by necessity time invariant (following Mo and Abdalla 1998). Both the breadth (48 states and four livestock species) and depth (29 years) of previously published work are extended in this analysis. A key assumption here is clearly that recent behavior in the livestock policy arena is representative across time in addition to being informative across space.

\section{Methodological Approach}

The typical approach for dealing with panel data is the error components model, which is specified as:

$$
Y_{i t}=X_{i t} \beta+Z_{i} \gamma+\alpha_{i}+\eta_{i t} \quad(i=1, \ldots, N ; t=1, \ldots T),
$$

where the $X_{i t}$ and $Z_{i}$ are time-varying and time-invariant observations on the explanatory variables, respectively. The $\alpha_{i}$ represents the unobservable effect believed to exist across units, while $\eta_{\mathrm{it}}$ is the usual stochastic error term. The observations are across $\mathrm{T}$ time periods and $\mathrm{N}$ units. In this research, the time series goes from 1969 to 1997, and is recorded for 48 states. The absence of the subscript $t$ on the $Z_{i}$ variables means that a time-invariant value is repeated across all time periods for a given unit $i$. In this analysis, the coefficients on these time-invariant $\mathrm{Z}_{\mathrm{i}}$, the regulatory and policy variables, are of central importance, which potentially creates several estimation challenges.

Depending on model specification, either a fixed or random effects model can be applied to derive estimates of the $\alpha_{i}$. The fixed effects model is the wellknown least squares with dummy variables, and the random effects approach is a 
version of Generalized Least Squares. Hsiao (1999) suggests that if an experiment involves individuals who are considered a random sample from a larger population, a random effects estimation is more appropriate. However, if the situation is one of analyzing just a few individuals and the sole interest lies in just these individuals, then individual effects would more appropriately be fixed, not random. Mundlak (1978) suggests that the $\alpha_{i}$ generally should be considered random effects. Reviews of the choice include Schmidt and Sickles (1984) and Seale (1990). Other factors can be a determinant of this estimation decision as well. For example, the estimates of the $\beta_{i}$ become similar between random and fixed effects when there exists a long time series in the panel. In addition, it is imperative that the explanatory variables be independent of the $\alpha_{\mathrm{i}}$ when using random effects.

The issues that need to be addressed here can be seen by observing a general representation of the panel data model, as presented in Hausman and Taylor (1981) (hereafter HT):

$$
\mathrm{Y}_{\mathrm{it}}-(1-\theta) \mathrm{Y}_{\mathrm{i} \bullet}=\left[\mathrm{X}_{\mathrm{it}}-(1-\theta) \mathrm{X}_{\mathrm{i} \bullet}\right] \beta+\theta \mathrm{Z}_{\mathrm{i}} \gamma+\theta \alpha_{\mathrm{i}}+\left[\eta_{\mathrm{it}}-(1-\theta) \eta_{\mathrm{i} \bullet}\right]
$$

The $\mathrm{Y}_{\mathrm{i} \bullet}=(1 / \mathrm{T}) \sum \mathrm{Y}_{\mathrm{it},} \mathrm{X}_{\mathrm{i} \bullet}=(1 / \mathrm{T}) \Sigma \mathrm{X}_{\mathrm{it}}$, and $\mathrm{Z}_{\mathrm{i} \bullet}=(1 / \mathrm{T}) \Sigma \mathrm{Z}_{\mathrm{i}}$, are unit, or state, means, averaged across all time periods. The $\theta$ is a parameter based on the variances of $\alpha_{i}$ and $\eta_{\mathrm{it}}$ and is expressed as $\theta=\left[\sigma_{\eta}^{2} /\left(\sigma_{\eta}^{2}+\mathrm{T} \sigma_{\alpha}^{2}\right)\right]^{1 / 2}$. The $\sigma_{\eta}^{2}$ is the variance of the time-varying error term and $\sigma_{\alpha}^{2}$ is the variance of the unobservable, time-invariant effect. At one extreme, if $\sigma_{\alpha}^{2}$ is zero, then $\theta$ goes to one, and the $\alpha_{i}$ have no variation and cease to exist. The appropriate estimation method is Ordinary Least Squares, as the $Y_{i \bullet}$ and $X_{i \bullet}$ terms drop out. If $\theta$ equals zero, then $\sigma_{\eta}^{2}$ is zero, and all variation across units would be due to the $\alpha_{i}$; the equation above thus becomes the dummy variable, or fixed effects estimator. For values of $\theta$ between zero and one, the random effects model can be used. However, because $\alpha_{i}$ still is in the error term, the $X_{i t}$ (after being differenced by the $(1-\theta) X_{i}$ term), need to be independent of the error term for consistent estimation.

The above discussion makes clear that the value of $\theta$ is critical in determining which estimation technique to use. The $\theta$ calculated for this regression is 0.004532 , suggesting that the fixed effects, or dummy variable estimator, is appropriate. We supplemented this perspective with three tests. First, an F-statistic was calculated for the dummy variables in the fixed effects model with the timevarying variables, and it rejected the null hypothesis of no individual effects $\left(F_{47,1336}=27.97, P\right.$-value $\left.=0.0000\right)$. Likewise, a LaGrange Multiplier test by Breusch and Pagan for random effects rejected the null of no random effects $\left(X_{1}=17,510\right.$, $\mathrm{P}$-value $=0.0000$ ). Finally, to distinguish between these two results, a Hausman test rejected the null of random effects in favor of the fixed effects model $\left(\mathrm{X}_{\mathbf{8}}=\right.$ $18.86, P$-value $=0.0156)$ (all of these tests are discussed in Greene 2000). This result 
is further confirmed because we have a long time series, for which the fixed effects approach is the limiting model, and we are covering virtually the entire population in the analysis, again a conceptual argument in favor of fixed effects.

It is also clear from Equation 3 above that the $Z_{\mathrm{i}}$ variables are affected, as they enter OLS in their original form when $\theta=1$ and drop out of the equation when $\theta=0$. Thus, all time-invariant variables are eliminated when using fixed effects, and $\gamma$, the coefficients on the environmental variables of interest here, cannot be estimated. Building on HT, a two-stage method is used for estimating $\hat{\gamma}_{\mathrm{i}}$ when the fixed effects model is preferred. The first stage is the usual fixed effects model on the time varying variables. The second stage, outlined in HT, is based on a regression of the $Z_{\mathrm{i}}$ variables on transformed residuals from the first stage.

The final issue is to make sure that the $Z_{\mathrm{i}}$ variables are independent of the error terms in the second stage estimation. In other words, instruments are needed to purge the correlation between the $Z_{\mathrm{i}}$ and the $\alpha_{\mathrm{i}}$. HT show that more uncorrelated time-varying variables must exist than correlated $\mathrm{Z}_{\mathrm{i}}$ for this regression to work. Here we assume that all time-varying variables are independent of the error term and all time-invariant effects are correlated. We make this assumption because the time-varying effects are generally well understood in the industry, and have been acted upon, so that any variation from the levels found in the variables themselves across states is random and probably uncorrelated with $\alpha_{i}$. However, we expect that any of the $Z_{i}$ could be correlated because of the rough proxies used, and the recent rise in environmental concerns, which together may lead to systematic deviations in the error that are correlated with the $Z_{i}$.

\section{RESULTS}

Increases in state environmental regulation are expected to result in smaller animal inventories due to environmental compliance costs. However, these unique effects can only be determined when examined in the context of other, more traditional factors affecting livestock industry location. Table 3 presents estimates of the influences of state-level environmental policies on livestock inventories using the two-step fixed effects model outlined in the previous section, which also controls for other factors besides regulation. The dependent variable is the sum of the livestock inventories of four livestock species (beef cattle, dairy cows, hogs, and poultry). The estimated relationship explains 98.6 percent of the variation in state livestock inventory based on the first stage fixed effects model, and 26.3 percent of the second stage estimation using the time-invariant environmental variables.

As expected, the higher the local slaughter capacity (Slaught) relative to animal inventories, the greater the tendency to locate livestock within a region. Likewise, property tax (Protax) is negatively correlated with inventories and is significant, consistent with our hypothesized directions. The unemployment variable (Unemp) is also in line with our expectations, as it is positive and significant. These results suggest that important business climate variables do have an effect 
on industry location. The natural endowment (Precipt) variable showed predicted signs but was statistically insignificant. Our land value measure (Landval) was statistically insignificant and directionally incorrect. The mixture of urban, rural agricultural, and nonagricultural influences in this variable may be too diverse for this to be a clear measure of impacts on livestock operations.

TABLE 3

Fixed Effects, Two-Stage Hausman-Taylor Regression Results

\begin{tabular}{lrrrrr}
\hline Variable & Coefficient & Std. Error & t-Statistic & Prob. & Elasticity \\
\hline UNEMP & $22,820.7$ & $5,872.0$ & 3.88 & 0.0001 & 0.049 \\
PROTAX & $-14,063.6$ & $3,811.8$ & -3.69 & 0.0002 & -0.034 \\
PRECIPT & -925.0 & $1,826.0$ & -0.51 & 0.6125 & -0.012 \\
LANDVAL & 12.8 & 25.6 & 0.50 & 0.6170 & 0.004 \\
POPDEN & $2,549.1$ & 445.3 & 5.73 & 0.0000 & 0.272 \\
BRATIO & -898.9 & 196.8 & -4.57 & 0.0000 & -0.053 \\
HRATIO & $1,475.3$ & $1,322.4$ & 1.12 & 0.2647 & 0.014 \\
SLAUGHT & $1,122,458.9$ & $494,223.1$ & 2.27 & 0.0233 & 0.003 \\
REGULA & $380,929.9$ & $35,044.7$ & 10.87 & 0.0000 & 1.447 \\
STAFF & $-1,029,360.1$ & $65,489.2$ & -15.72 & 0.0000 & -0.834 \\
LEVF & $-1,240,732.9$ & $405,308.7$ & -3.06 & 0.0023 & -0.249 \\
CORP & $6,447,437.5$ & $691,800.3$ & 9.32 & 0.0000 & 0.297 \\
ZONING & $557,777.5$ & $717,737.3$ & 0.78 & 0.4370 & 0.029 \\
\hline
\end{tabular}

$\mathrm{T}=$ Observations over time $=29 \quad \mathrm{~N}=$ Cross Sections Used $=48$

$\mathrm{N}^{*} \mathrm{~T}=1,392$ (Balanced Panel)

For First Stage Fixed Effects Model:
R-squared
0.986
Adj. R-squared
0.986
Mean dependent variable
S.D. dependent variable
$2,889,345$
$2,846,981$

For Second Stage Time Invariant Model:

$\begin{array}{llll}\text { R-squared } & 0.266 & \text { Mean dependent variable } & 2,889,064 \\ \text { Adj. R-squared } & 0.263 & \text { S.D. dependent variable } & 2,826,039\end{array}$

Unexpectedly, the ratio between beef prices and feed costs (Bratio), a rough indicator of profitability, was negatively correlated with state livestock inventories. Among all livestock categories included in total inventories, beef cattle should be the most responsive to beef prices. However, the beef cattle industry has demonstrated the least relative inventory variation over time and place, and states experiencing the largest changes in livestock inventories were not traditional beef-producing states. Therefore, one explanation for this unexpected result is that strong increases in poultry and hog production in non-beef cattle states drive major changes in the dependent variable, rather than reactions within the beef cattle industry.

The hog-corn price ratio had a positive but only marginally significant effect on total livestock inventories, challenging the interpretation of business factors driving inventory change. ${ }^{2}$ One explanation is derived from the nature of NASS data. NASS data for the hog industry are not differentiable by operation type (farrow, nursery, and finish). While hog operations have traditionally been

${ }^{2}$ We use the term "marginally" for the significance level of 1.12 because it indicates that a variable should be retained in a model because it raises adjusted $R^{2}$ and suggests an appropriate specification, yet it cannot be interpreted as a conventionally significant variable (Johnston 1984). 
farrow-to-finish, all recent growth in the industry has been specialized. Since feed is only about 10 to 20 percent of production costs in a farrowing operation and closer to 80 percent of production costs in a hog finishing operation, using feed cost as an overall industry driver may create a significant data concern. Therefore, it is consistent to argue that, taken together, these unexpected effects may be artifacts of the data used rather than a directly interpretable relationship between beef and hog inventories and profitability.

The last unexpected result among the traditional variables was about human-livestock interaction, or competition for private lands (Popden), which was found to correlate positively with livestock inventories. This result would seem to capture the trend in livestock operation location into states conventionally thought to have high population densities, such as California, New York, and Illinois, and away from low-density states in some cases, such as Wyoming. It implies that location near a population center still is attractive despite an improved transport network and the availability of lower costs in areas more distant from the consuming population.

Our time-invariant variables used to assess the role of policy in industry location provide a clear picture of results. The variables related to the written stringency of regulations tended to yield positive influences on livestock inventories. As expected, protective agricultural districting (Zoning) was positively correlated, though causally indeterminate, with livestock inventories. The variable summarizing the numbers of environmental regulations in place in a state (Regula) was positive and significant, so that regulation goes hand in hand with higher livestock inventories. This supports the "industry drives policy" hypothesis, implying that states react to greater livestock activity by creating more policies.

State legislation to restrict corporate ownership of livestock (Corp) is positively related to livestock inventories, counter to the findings of Krause (1983) and Matthey and Royer (1999). This result is somewhat unexpected because large operations are typically associated with a significant corporate presence. Restrictions on corporate ownership should, therefore, reduce the number of large operations and, probably, the overall size of the industry. However, the seven states restricting corporate ownership also tend to have important agricultural sectors, and most of them have maintained their relative positions as major producers. ${ }^{3}$ Among the seven, only South Dakota and Minnesota have experienced large declines in relative rankings (Table 2). There are at least two possible explanations: large operations have either been "grandfathered in" and can grow significantly without hindrance from regulation; or firms may have found legal loopholes to the corporate label, such as limited partnerships and family corporations, rendering anticorporation legislation largely ineffective in guiding industry behavior.

In contrast to the written stringency results, the tendency to fine operations for noncompliance with regulations (Levfine) was significant and negatively related to inventories. This suggests that the written stringency of regulations is ${ }^{3}$ The states that have this legislation in place include Iowa, Nebraska, Kansas, Wisconsin, Minnesota, North Dakota, and South Dakota. 
less important than the state's willingness to enforce them in industry location decisions, implying that policy guides industry location rather than the converse. The number of staff dedicated to the regulatory compliance (Staff) is also negatively correlated with inventories, so that adding staff seems to raise costs of noncompliance in the eyes of business and affect location inversely.

The marginal effects and relative influence of the explanatory variables on livestock inventories are illustrated through the calculation of elasticities (Table 3). It is expected that most time-varying traditional factors (i.e., natural endowment, economic factors, and business climate variables) should have only a small effect, as they have been known for many years and have not varied substantially over time. This was generally confirmed. Indeed, the only factor with a high elasticity, population density (Popden) at 0.27 , is arguably not a traditional factor, as it appears to reflect the considerable movement of livestock operators into states that have high populations. Other traditional factors that demonstrated at least some effect (elasticities around 0.05) included unemployment and the beef-corn ratio, and, to a slightly lesser extent, property tax. Surprisingly, slaughter capacity (Slaught) has a very low elasticity, at 0.003 , which may be related to the way we defined the variable. Because it is a ratio of capacity to inventories, changes are small and probably represent a general trend of the livestock industry in a given state across time. Therefore, net of the other factors affecting the location decision, these effects are small.

The time-invariant environmental policy variables are of primary focus in this analysis. The calculated elasticities on the included regulatory variables range widely, but are usually higher than the traditional, time-varying variables. The strength of these policy-inventory relationships is in keeping with our general hypothesis that environmental policy and livestock inventories are related. The political reaction is the most elastic, as a 1 percent change in the number of regulations (Regula) is associated with a 1.45 percent change in livestock inventories in a state. Restrictions on corporate ownership of livestock (Corp) demonstrated the second largest elasticity $(0.297)$ among the written policy influences. (The Zoning elasticity is essentially zero, as denoted by its lack of significance).

The variables indicating the actual economic costs of noncompliance, or a state's willingness to enforce environmental regulations, are Levfine and Staff, both of which had negative effects. Between these two, adding Staff had the largest negative elasticity, at -0.834 . Analogously, a 1 percent increase in the propensity to levy fines (Levfine) implies a 0.249 percent decrease in state livestock inventories.

\section{IMPLICATIONS AND CONCLUSIONS}

Recent livestock industry trends toward greater industrialization, concentration, and vertical coordination may have environmental and social implications (Martin and Zering 1997). National, state, and local environmental policy may seek to redress these potential social and environmental effects. Unfortunately, little information connecting industry performance with policy is in evidence. Policy 
effectiveness (changes in water quality measures) and enforcement (number, amount, and date of fines or operation closures) are not readily available across states. Lacking policy effectiveness and enforcement information, it is difficult to infer whether a lack of correlation between environmental policy and location decisions are due to highly efficient policies (those which reach social water quality objectives without increasing livestock production costs) or completely ineffectual policies (no enforcement).

Generally speaking, our results indicate that some traditional factors considered in the analysis are important to farm-level and total inventory location decisions, but that the more substantial impacts derive from environmental and management-related policies. Although environmental policy factors may increase production costs differentially across state lines, competitive advantages obtained from sunk costs in infrastructure, marketing channel development, or other natural factors have been more compelling than increased regulatory compliance costs in general. Due to the time-invariant nature of our policy data and the lack of policy performance information, our analysis provides ample room for interpretation in support of the contention that either industry drives policy or the converse, but it does not allow us to rule out either possibility. We can conclude, however, that actual enforcement of regulations seems to have an important role in stocking and location decisions of the livestock industry and that enforcement is more influential than the written stringency of the regulations. In the specific cases of agricultural districts and laws restricting corporate ownership of livestock, the reduction of production costs provided by zoning does not appear to be sufficient to affect livestock firm location and inventory decisions, and corporate ownership regulations have not limited the growth of the industry where other attractive location factors have been present.

We have attempted to relate state-level environmental policies to location decisions of the livestock industry across the entire United States. A number of interesting results have come from this effort. However, the extent of the impact on water and air quality and some directions of the regulatory effect are not clear. To improve the precision of our conclusions, we suggest future analyses attempt to incorporate entry and exit information (as manufacturing sector studies have done), compile more comprehensive enforcement and effectiveness information over time, and make explicit consideration of the potential endogeneity of environmental policy and the size of the livestock industry.

\section{REFERENCES}

Bartik, T.J. "The Effects of Environmental Regulation on Business Location in U.S." Growth and Change 19 (3) (Summer 1988), 22-44.

Edelman, M., H.M. Harris, A. Seidl, and M.L. Warner. "1998 National Survey of State Animal Confinement Policies." Animal Confinement Policy Task Force, 1999. Data may be accessed at http://cherokee.agecon.clemson.edu/ confine.htm. 
Gomez, I.A., H.A. Love, and D.M. Burton. "Analysis of the Effects of Environmental Regulation on the Pulp and Paper Industry Structure." Selected paper presented at the meetings of the American Agricultural Economics Association, Salt Lake City, Utah, 1998.

Gray, W.B. "Manufacturing Plant Location: Does State Pollution Regulation Matter?" NBER Working Paper 5880. Cambridge, Mass.: National Bureau of Economic Research, 1997.

Greene, W. "Models for Panel Data." In Econometric Analysis, 557-689. 4th ed. Upper Saddle River, N.J.: Prentice Hall, 2000.

Hausman, J.J., and W.E. Taylor. "Panel Data and Unobservable Individual Effect." Econometrica 49 (6) (1981), 1377-1398.

Henderson, J.V. "Effects of Air Quality Regulation." American Economic Review 86 (4) (1996), 789-813.

Hsiao, C. "Simple Regression with Variable Intercepts." In Analysis of Panel Data, 25-70. Econometric Society Monographs no. 11. Cambridge: Cambridge University Press, 1999.

Hubbell, B.H. "Entropy Based Measurement of Geographic Concentration in U.S Hog Production." FS-97-02. Dept. of Agricultural and Applied Economics, University of Georgia, 1997.

Johnston, J. Econometric Methods. 3rd ed. New York: McGraw-Hill, Inc., 1984.

Krause, K.R. "Corporate Farming; Importance, Incentives, and State Restrictions." USDA ERS Agricultural Economic Report No. 506. Washington, D.C., 1983.

Levinson, A. "Environmental Regulations and Manufacturers' Location Choices: Evidence from the Census of Manufactures." Journal of Public Economics 62 (1996), 5-29.

Martin, L.L., and P.E. Norris. "Environmental Quality, Environmental Regulation and the Structure of Animal Agriculture." Feedstuffs 70 (1998), 18.

Martin, L.L., and K.D. Zering. "Relationship between Industrialized Agriculture and Environmental Consequences: The Case of Vertical Coordination in Broilers and Hogs." Journal of Agricultural and Applied Economics 29 (1) (1997), 45-56.

Matthey, H., and J.S. Royer. "Testing the Impact of Corporate Farming Laws on Hog Industry Growth: A Partial Adjustment Approach." Selected paper presented at the meetings of the American Agricultural Economics Association, Nashville, Tenn., August 1999.

McConnell, V.D., and R.M. Schwab. "The Impact of Environmental Regulation on Industry Location Decisions: The Motor Vehicle Industry." Land Economics 66 (1990), 67-81.

McFadden, D. "Conditional Logit Analysis of Qualitative Choice Behavior." In Paul Zarembka (ed.) Frontiers in Econometrics, 105-142. New York: Academic Press, 1974.

Metcalfe, M. "State Legislation Regulating Animal Manure Management." Review of Agricultural Economics 22 (2) (2000), 519-532. 
Metcalfe, M., and J.C. Beghin. "Piecemeal Reform of Trade and Environmental Policy when Consumption Also Pollutes." Working Paper 99-WP 209. Center for Agricultural and Rural Development, Iowa State University, 1999.

Mo, Y., and C. Abdalla. "Analysis of Swine Industry Expansion in the U.S: The Effect of Environmental Regulation." Discussion paper, Staff Paper 316. Department of Agricultural Economics and Rural Sociology, The Pennsylvania State University, 1998.

Mundlak, Y. "On the Pooling of Time Series and Cross Section Data." Econometrica 46 (1978), 69-85.

Schmidt, P., and R. Sickles. "Production Frontiers and Panel Data." Journal of Business and Economic Statistics 2 (4) (1984), 367-374.

Seale, J.S. "Estimating Stochastic Frontier Systems with Unbalanced Panel Data: The Case of Floor Tile Manufactories in Egypt." Journal of Applied Econometrics 5 (1) (1990), 59-74.

Thurow, A.P., and J. Holt. "Induced Policy Innovation: Environmental Compliance Requirements for Dairies in Texas and Florida." Journal of Agricultural and Applied Economics 29 (1) (1997), 17-36.

U.S. Department of Agriculture. National Agricultural Statistics Service (USDANASS). "1997 Census of Agriculture." Washington, D.C., 1999a. "Historical Data." Washington, D.C., 1999b. 
